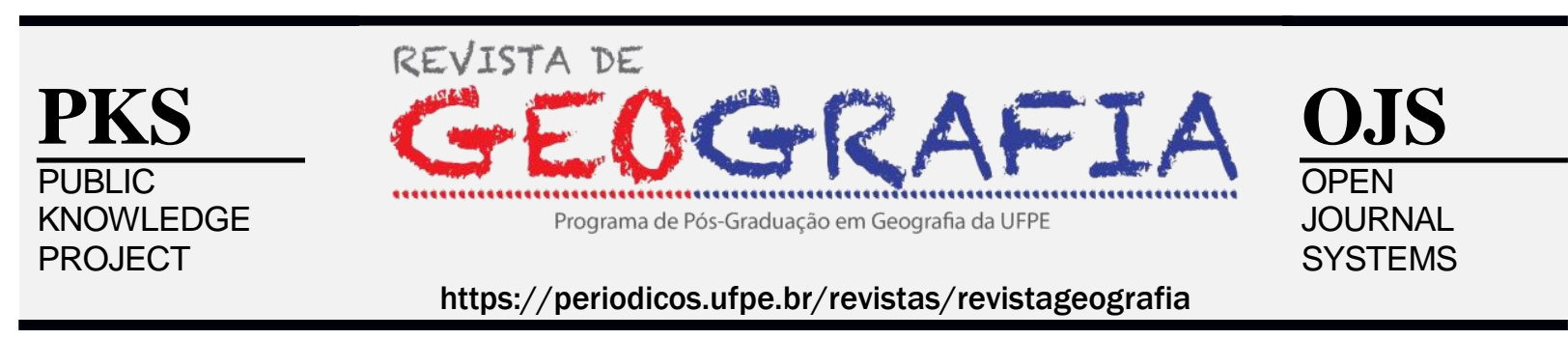

\title{
ANÁLISE DA CARTOGRAFIA SOCIAL NA AUTORREPRESENTAÇÃO DAS COMUNIDADES TRADICIONAIS E O CONFLITO DO DESENVOLVIMENTO
}

\author{
Girlan Cândido da Silva ${ }^{1}$, Claudio Ubiratan Gonçalves ${ }^{2}$ \\ ${ }^{1}$ Doutorando do Programa de Pós Graduação em Geografia da UFPE. E-mail:girlancandido@gmail. \\ ${ }^{2}$ Docente do Programa de Pós Graduação em Geografia da UFPE. E-mail: biragrario@gmail.com
}

Artigo recebido em 24/02/2019 e aceito em 14/06/2019

\begin{abstract}
RESUMO
Os territórios das comunidades tradicionais tem sido frequentemente alvo de cobiça e disputa provocado pelo avanço do grande capital, detentor de terras para expansão de suas fronteiras, deixando-as vulneráveis tanto devido à ação deste processo capitalista bem como com a ausência de políticas estatais voltadas para a defesa destes territórios. A cartografia social vem de certa forma suprir esta necessidade, visto que, com o processo autorrepresentativo referenciado, tais comunidades podem ser "vistas" e reconhecidas no documento mapa, dando-lhes assim subsídios para que haja a resistência e permanência em seus territórios.
\end{abstract}

Palavras-chave: Cartografia social; território; Comunidades tradicionais

\section{ANALYSIS OF SOCIAL CARTOGRAPHY IN THE AUTHOR REPRESENTATION OF TRADITIONAL COMMUNITIES AND THE CONFLICT OF DEVELOPMENT}

\begin{abstract}
The territories of traditional communities have often been the object of greed and dispute provoked by the advance of the great capital, landowner for the expansion of its borders, leaving them vulnerable both due to the action of this capitalist process as well as the absence of state policies directed for the defense of these territories. The social cartography comes to some extent to meet this need, since with the referenced self-representation process, such communities can be "seen" and recognized in the map document, thus giving them subsidies for resistance and permanence in their territories.
\end{abstract}

Keywords: Social cartography, territory, traditional communities 


\section{INTRODUÇÃO}

A cartografia social tem sido vista como sendo uma das alternativas de resistência contra as situações de conflito que envolve disputas territoriais, principalmente em comunidades tradicionais afetadas diretamente pelo grande capital que, por sua vez, tentam desterritorializar tais comunidades. Tal construção de um mapa participativo onde as comunidades têm a possibilidade de se autorepresentar, possibilita a criação de mais um dispositivo de luta contra tentativas de expulsão, e como tal, esta representação se faz essencial em territórios complexos que sofrem investidas continuamente pelo grande capital.

\section{A CARTOGRAFIA SOCIAL COMO INSTRUMENTO DE LUTA E RESISTENCIA DAS COMUNIDADES TRADICIONAIS: UMA NOVA FORMA DE REPRESENTAÇÃO DO ESPAÇO}

Essencialmente no estado de Pernambuco, a mesorregião da mata Pernambucana e o Sertão Pernambucano são, historicamente, palcos de conflitos e tensões territoriais não somente pelo grande capital, mas também pela própria investida do Estado que acaba criando situações desfavoráveis às comunidades tradicionais (agricultores familiares, agricultores camponeses, quilombolas, fundo de pasto, etc.) frente ao processo de desenvolvimento e modernização pautado na dinâmica desigual e combinada do grande capital nas regiões. Assim, acredita-se que a cartografia social poderá ser um instrumento técnico-científico que possibilita a criação de documentos cartográficos a partir do olhar do sujeito social frente a sua realidade local.

É notório que os grandes empreendimentos trazidos pelo Estado de Pernambuco têm causado grandes impactos de cunho socioeconômico para determinadas comunidades na Mata e no Sertão, essencialmente em tempos políticos complexos, acarretando ônus a essas referidas comunidades. Estas por sua vez, são prejudicadas pelo avanço do desenvolvimentismo estatal o que propicia um desfavorecimento no sentido territorial a essas comunidades.

Com base nestas considerações, faz-se necessário, por meio de uma cartografia participativa, uma intervenção e identificação territorial por parte dos povos tradicionais ao seu próprio território. É possível, portanto, a partir deste mecanismo de construção e 
elaboração de sua própria realidade, sendo reproduzida em um documento (mapa), gerar mais um instrumento de luta contra tais avanços e problemas às comunidades tradicionais.

Ações atuais apontam o surgimento de outras cartografias denominadas como "novas cartografias sociais", "cartografias participativas", "cartografias da ação", "contramapeamentos", entre outras. Tais cartografias se distinguem pela representação de aspectos da realidade (fenômenos, processos, elementos, atores, ações, etc.) que geralmente são pouco valorizados nas representações espaciais cartográficas hegemônicas - aspectos transformados em "nãoexistências", como nos diz Boaventura de Souza Santos (1991) em suas pesquisas.

Estas também diferenciam-se pelo surgimento de outros modos de fazer representações espaciais, utilizando a partir de processos de construção de mapas calcados na participação, contemplando outras formas de se fazer representar com suas diferentes relações de poder e saber e sobretudo rompendo com a rigidez da cartografia tradicional. Tais mapas utilizam uma soma de conhecimentos que permeiam os produtores cartográficos e os grupos sociais envolvidos no processo. (SANTOS, 2012).

As iniciativas de mapear comunidades ou populações que se encontram em situação de conflito, principalmente, foram difundidas mundialmente a partir dos anos 90 do século XX. Assim sendo, tal forma de cartografar tem como proposta principal a de incluir as populações tradicionais ou locais ou aquelas comunidades que ocupam territórios em estado de conflito nos mapas, onde tais mapas trazem elementos existentes no seu cotidiano, suas bases referenciais de existência e de resistência, a partir de uma base cartográfica.

O mapeamento participativo tem como princípio dar visibilidade às inúmeras camadas sociais, nos quais veem no contexto da cartografia uma forma rica de mapear os problemas existentes em suas comunidades ou territórios bem como suas identidades. Assim sendo, povos como:

(...) às mulheres quebradeiras de coco, ribeirinhos, homossexuais, quilombolas, indígenas, faxinalenses, artesãos, extratores, pescadores, seringueiros, castanheiros, carvoeiros, etc. (...). Com o 


\section{Revista de Geografia (Recife) V. 36, No. 2, 2019 - ISSN: 2238-6211}

apoio de sindicatos, associações, movimentos, cooperativas, esses grupos têm utilizado o mapa social "como forma de afirmar direitos territoriais" em diferentes contextos (GORAYEB, 2014).

Para estas comunidades e povos, a representação junto a seu território se faz importante, pois para elas, o território assume representação muito maior do que um espaço de sobrevivência e de relações de poder e disputa. Segundo o ponto de vista descrito por Gorayeb

“a ocupação do território é vista como algo gerador de raízes e identidade: um grupo não pode ser compreendido sem o seu território, no sentido de que a identidade sociocultural das pessoas está, invariavelmente, ligada aos atributos da paisagem. Nessa perspectiva, os territórios das comunidades tradicionais se caracterizam por serem, mais fortemente, ligados ao campo simbólico, e não simplesmente às relações de poder, propriedade ou controle político da hegemonia econômica circundante. Ou seja, o sentimento de pertencimento à terra, à história, às lutas, à identidade, às práticas, às vivências, aos rituais, entre outros, se aglutinam formando uma conjuntura legitimadora dos territórios vividos" (GORAYEB, 2014).

Deste modo, Acselrad (2014) afirma que os mapeamentos em sua grande maioria acontecem devido a problema de conflito existentes em determinados territórios nos quais as comunidades que estão sendo ameaçadas sentem a necessidade de construção de sua representação no território que, em linhas gerais, "entra em conflito com a territorialidade privada, dos grandes projetos do agronegócio, das grandes mineradoras, dos projetos de hidrelétricas, etc.”. Por sua vez, tentam se autoafirmar suas identidades ameaçadas pelos projetos do grande capital.

Neste sentido, Santos (2014) nos informa que estes e vários outros motivos e objetivos devem ser elencados como motivadores para confecção dos mapas e que denotam 
as decisões estratégicas tomadas em torno dele, inclusive dentro de uma realidade voltada a cartografia social participativa.

Contudo, as autorrepresentações demonstram alguns fatos ora limitantes. Os principais pontos de impasse acerca do problema enfrentado referente a cartografização de povos tradicionais suscita na falta de conhecimento técnico adequado por parte da comunidade para referenciar seu próprio território. Portanto, faz-se necessário a realização de oficinas técnicas para que a comunidade possa se autorepresentar.

Do mesmo modo, as formas de se cartografar as comunidades e povos tradicionais diferem da forma tradicional de se fazer mapas, pois os mapas sociais, de acordo com Acselrad (2014) são as formas de representações elaboradas pelos povos que ocupam um determinado território e dentro desta representação está suas formas de vida, de trabalho, seus espaços que representam tanto sua simbologia quanto sua afeição pelo espaço (ACSELRAD, 2014 In GORAYEB, 2014). Esta nova forma de se cartografar pode entrar em conflito com as tradicionais convenções e normativas cartográficas.

Assim sendo, o mapa produzido não é hermeticamente fechado como os elaborados pela cartografia tradicional, visto que existe uma representação da comunidade da forma que ela se enxerga enquanto sociedade em um mapa o que, por sua vez, está em constante processo de construção. Não obstante, os processos que envolvem as metodologias na elaboração dos mapas voltados para a cartografia social devem sempre conter os métodos participativos de transferências de informação e de produção entre pesquisador e comunidades bem como do conhecimento cientifico e essa mobilização na construção do mapa ajuda a fortalecer a mobilidade dos grupos nos quais se apropriam da ferramenta cartográfica conforme sua necessidade e bem como a participação dos envolvidos que não fica restrito apenas a elaboração do mapa podendo surgir demandas e direitos podem ser reconhecidos, possibilitando estratégias coletivas de ação (GORAYEB, 2014).

Entretanto, o empoderamento destas comunidades no que tange ao mapeamento participativo perpassa pelo domínio dos softwares básicos para a construção ou manipulação de mapas, e este inicialmente pode ser visto como um desafio inicial uma vez que será necessário um aprofundamento conceitual e de manuseio de programas e produtos para confecção de seu próprio mapa. 
As disputas territoriais entre comunidades envolvidas e as obras do grande capital também podem se traduzir em um ponto de impasse no momento da representação cartográfica, uma vez que áreas territoriais destas comunidades estão sendo tomadas pelos grandes empreendimentos ou pelos grandes latifundiários de terras que tem condições de aquisição de mapas ou imagens de satélite, indo em busca destes territórios tradicionais.

Estudos similares foram feitos na Amazônia brasileira que também sofre com impactos semelhantes ao que é visto na região de Pernambuco a ser investigado. O professor Alfredo Wagner, da Universidade do Estado do Amazonas, ainda na década de 1990 do século XX desenvolveu o projeto da Nova Cartografia Social. Tal projeto visava, sobretudo, o mapeamento de comunidades que foram impactadas pelo projeto

Grande Carajás, que apontava a exploração de minérios proporcionado pela Vale S/A, na área da Amazônia Legal. Tais estudos resultaram em mapas participativos, elaborados pela própria comunidade e servindo como instrumentos utilizados para fazer valer os direitos desses grupos frente a grandes empreendimentos econômicos.

Outro problema encontrado é que a elaboração e construção de mapas, por exemplo, deixou de ser uma variável pertencente às ciências geográficas e passou também a ser utilizado por outras ciências tais como a antropologia. Dentro da cartografia social, os estudos e construções de mapas assumem atualmente um caráter e um rigor mais antropológico do que geográfico propriamente dito, o que de certo modo pode trazer consigo dificuldades como a falta de uma melhor interpretação acerca dos problemas relacionados ao espaço geográfico.

Tal realidade que aqui se apresenta, tenta trazer de volta a aplicabilidade conceitual e de leitura de um mapa para a ciência geográfica, mostrando que os processos adotados pela cartografia social também podem (e devem) ser apropriados pela geografia, pois, a partir da construção de um mapa participativo, podemos ter a possibilidade de compreender as dinâmicas existentes em um determinado território sob a ótica da própria comunidade e, a partir dai, ter uma melhor noção de como tais comunidades estão sendo de fato impactadas pelos processos dominantes do grande capital.

Os mapas atualmente são considerados ferramentas fundamentais para a leitura e interpretação territorial. O produto cartográfico - mapa - pode ser utilizado em todas as 
atividades que requer ou que apresente o território como pano de fundo, sendo considerado como um documento essencial ao reconhecimento de comunidades ou de legitimação territorial.

Contudo, tal produto geralmente é utilizado pelo grande capital ou pelos grandes empreendedores que estejam almejando novos territórios para expansão dos seus negócios. E justamente por ser um produto caro e que requer uma mão de obra especializada, nem todos têm condições de aquisição.

Assim como os grandes empreendedores, as comunidades tradicionais como já dito, também necessitam deste instrumento como forma de autoafirmação e de legitimação do seu território, justamente como forma de obtenção de um instrumento representativo de seu território, e com isso legitimar seus espaços de vivência e convivência social. Para isso, a cartografia social está para suprir esta lacuna que anteriormente só os grandes empreendedores podem arcar. E o produto final, o mapa, proposto pela comunidade se torna um importante instrumento para tais comunidades e evitando, com isso, uma possível disputa territorial com os detentores do grande capital.

Com isso, a partir da exibição de uma cartografia participativa, a ciência geográfica em muito pode contribuir para uma melhor compreensão e interpretação dos problemas relacionados tanto com a própria comunidade quanto também a contextos e conceitos geográficos que outras ciências assim não dispõe e domina, bem como a cartografia social pode enriquecer ainda mais a ciência geográfica a partir de um novo método de se fazer cartografia.

Neste caso o uso da cartografia social, tendo em vista o mapa como produto final, pode contribuir com a ajuda dos métodos, técnicas e conceitos da Ciência Geográfica para a compreensão de um processo de reconstrução territorial sob o ponto de vista das comunidades a partir da análise destes mapas construídos bem como criar subsídios que possibilitem a resistência das referidas comunidades frente à dinâmica produtiva combinada e desigual do grande capital.

Assim, a cartografia social no contexto geográfico apresenta como finalidade: a $\frac{\text { aplicação do uso e recurso da cartografia como forma de "geograficizar" o espaço das }}{\text { Silva e Gonçalves, } 2019}$ 
referidas comunidades, trazendo o debate da cartografia social como tema para a ciência geográfica; A identificação e mapeamento de perfil da população impactada pelas atividades ligadas às transformações do grande capital no Estado de Pernambuco ou onde se fizer necessário a sua aplicação; Subsidiar as populações tradicionais necessitadas para que deem visibilidade (sócio, cultural e econômica) ao seu território, através da participação em oficinas de cartografia social; Analisar as novas dinâmicas territoriais promovidas pelo Estado a partir dos mapas produzidos pelas comunidades e de que forma o mesmo influencia nas territorialidades das referidas comunidades tradicionais, dentre outras aplicações.

\section{A CARTOGRAFIA SOCIAL: UM ENSAIO TEÓRICO}

Tendo em vista a carga conceitual acerca do trabalho, e em concordância com Santos (2012, p. 5), define-se Cartografia social como sendo uma:

(...) cartografia elaborada pelos próprios grupos sociais que ela representa no mapa, um processo no qual membros de um determinado grupo registram quem são, onde e como vivem. O que se busca, portanto, não é mapear os grupos, mas sim, permitir aos grupos que eles próprios se mapeiem, e este processo de (auto) mapeamento é denominado, segundo o próprio núcleo, de "mapeamento situacional".

Com isso, a representação cartográfica participativa permite a exibição de determinados conflitos territoriais como maneira de representá-la e fazer com que a comunidade possa lutar pelos seus direitos. Este é o verdadeiro significado da cartografia social, bem como seu papel de denunciar as irregularidades exercidas pelos conflitos em prol do grande capital, como acontece na maioria dos casos.

A cartografia social emprega uma metodologia diferenciada em seu plano de trabalho. Assim como afirma Santos, a forma de se construir um mapa não fica apenas a cargo do técnico, mas sim aplicando uma: 
(...) metodologia participativa, "onde os próprios sujeitos coletivos, que conhecem e vivenciam os impactos negativos das atividades degradadoras existentes em suas localidades, identificam os conflitos e constroem o mapeamento" (SANTOS, 2012, p. 4).

No que cerne à importância acerca das representações das comunidades pela cartografia, afirma Acselrad que "quando as comunidades pensam em fazer sua própria cartografia, elas não estão simplesmente retratando o espaço físico, mas reafirmando seus modos de vida", assim a "produção de mapas passou a integrar, as lutas simbólicas envolvidas no processo de produção cultural da paisagem e de seus elementos materiais" (ACSELRAD, et alii, 2010, p. 5).

Deste modo, observa-se que tais experiências de cartografar as realidades de determinadas comunidades não ficam restritas apenas a uma única e exclusiva visão que é a de delimitação territorial. Neste contexto deve-se considerar também a representação social embora tais aspectos de construção dos próprios mapas por parte das comunidades também perpasse pelos conflitos fundiários, étnicos e ambientais nos quais tais atores sociais estão em disputa pela apropriação de seu território.

Santos (2012) vai mais além ao afirmar que as representações cartográficas elaboradas a partir de uma cartografia participativa podem contribuir em outras deliberações bem como:

“(i) dar visibilidade aos conflitos socioambientais na região; (ii) ser instrumento de pressão e denúncia; (iii) auxiliar no diagnóstico local, desmistificando o que tem sido chamado por „desenvolvimento e progresso "e para a Amazônia; (iv) caráter educativo no sentido de possibilitar a organização e mobilização; (v) viabilizar o diálogo com dados oficiais; (vi) contribuir no planejamento das ações das organizações populares, indicando caminhos estratégicos e alianças/parcerias" (SANTOS, 2012, p. 4). 
Contudo, basicamente, as delimitações e qualificações territoriais a partir da visão dos próprios moradores revelariam a importância desse espaço para a comunidade, apontando zonas conflituosas, potencialidades e áreas de ação prioritária, uma vez que tal conhecimento produzido pode servir como estratégias de produção e controle sobre o território.

A associação do trabalho de cunho acadêmico com os saberes locais poder-se- á realizar como uma forma de mapeamento participativo, apresentando como resultado uma representação cartográfica elaborada em conjunto a partir da maneira pela qual esta própria comunidade concebe sua espacialidade. Como consequência, atingir-se-ia uma maior e mais efetiva reafirmação da existência desses territórios que se necessite tal representação, seja ele de resistência ou não, diminuindo-se a invisibilidade que os fragiliza, a partir da autoafirmação ampliada da comunidade no território em questão.

A análise em questão está calcada no quantitativo-qualitativo, bem como fará parte de um estudo de caso visto que levar-se-á em conta a observação de comunidades tradicionais que serão investigadas. A referida pesquisa também será de caráter participativa, visto que a visão do observador sobre o fenômeno a ser investigado será levado em consideração para que haja a compreensão dos fatos investigados.

Quanto aos procedimentos desenvolvidos para uma pesquisa de cunho cartográficoparticipativo, os meios para a obtenção de dados são a entrevista, a intervenção por meio de oficinas direcionadas as práticas da cartografia social, a observação in loco dos processos de intervenção territorial por meio do Estado ou de outros agentes (caso este seja um fator determinante de conflito territorial) bem como das práticas da autocartografia que serão feitas pela comunidade a partir das oficinas, a aplicação de questionários e de analise documental acerca do produto final feito pela comunidade.

Também serão desenvolvidas entrevistas com os atores envolvidos no processo, com questões abertas para uma melhor avaliação, contudo elencaremos a forma de perguntas semi-estruturadas para uma melhor avaliação do problema ocorrido junto as comunidades. 
Tais registros podem ser feitos a partir de gravadores, cadernetas de campo, utilização de GPS e a partir de imagens de satélite e construção de croquis para que, a posteriori, seja geoprocessada em softwares específicos, tais como o Qgis ou similares.

\section{REFERÊNCIAS}

ACSELRAD, Henri. Cartografias sociais e território. Rio de Janeiro: Universidade Federal do Rio de Janeiro, Instituto de Pesquisa e Planejamento Urbano e Regional, 2008.

ACSELRAD, Henri. Sobre os usos sociais da cartografia. Rio de Janeiro: Universidade Federal do Rio de Janeiro, Instituto de Pesquisa e Planejamento Urbano e Regional, 2014. Disponível em: http://conflitosambientaismg.lcc.ufmg.br/geral/anexos/txt_analitico/ACSELRAD_He nri__Sobre_os_usos_sociais_da_cartografia.pdf

ACSELRAD, Henri; VIANNA JR, Aurélio, ET AL. Cartografia social e dinâmicas territoriais: marcos para o debate. Rio de Janeiro: Universidade Federal do Rio de Janeiro, Instituto de Pesquisa e Planejamento Urbano e Regional, 2010.

GORAYEB, Adriana. Cartografia Social e Populações Vulneráveis. Oficina do eixo Erradicação da Miséria, 2014. Disponível em: http://www.mobilizadores.org.br/wpcontent/uploads/2014/07/Cartilha-Cartografia-Social.pdf

RICARDO, Fany (org.). Terras Indígenas e Unidades de Conservação da natureza: o desafio das sobreposições. Instituto Socioambiental. São Paulo: 2004.

SANTOS, Renato Emerson dos. Disputas Cartográficas e Lutas Sociais: Sobre Representação Espacial e Jogos de Poder. XII Coloquio de Geocritica. Bogotá, 2012.

SANTOS, Boaventura de Souza. Uma cartografia simbólica das representações sociais: prolegômenos a uma concepção pós-moderna do direito Espaço \& Debates, vol. 33, Ano XI, 1991. 